\title{
LETTER
}

doi:10.1017/S1041610208007059

\section{Do elderly suicide rates influence the quantity of published geriatric psychiatry research? A cross-national study}

Suicide rates have traditionally been thought to increase with age (Shah and De, 1998). A recent cross-national study of 62 developing and developed countries has reported an increase in suicide rates with aging in males and females in only 25 and 27 countries respectively (Shah, 2007a). Public health initiatives are being developed in many countries to facilitate reduction in suicide rates including those in the elderly (e.g. Chiu et al., 2003; Shah, 2007b). Such initiatives in the U.K. included legislation requiring general practitioners to offer annual physical and mental examinations to those over the age of 75 years, the Defeat Depression Campaign organized by the Royal College of Psychiatrists and the Royal College of General Practitioners, the governmental "Our Healthier Nation" suicide reduction targets, the National Confidential Enquiry into Suicides and Homicides, the National Service Frameworks for Mental Health and for Older People, and the National Suicide Prevention Strategy (Shah, 2007b).

However, these public health initiatives need to be informed by high quality relevant research. This research, in addition to the epidemiology of suicides, identification of proximal and distal risk and protective factors for suicides, and efficacy and effectiveness of interventions to reduce suicide rates, should include wider research in the epidemiology of mental illness, risk and protective factors for mental illness and efficacy of treatment interventions for mental illness. A large fraction of published geriatric psychiatry research would include all the areas of research described in the last sentence. Therefore, a cross-national study examining the relationship between elderly suicide rates and the total number of research publications in two leading geriatric psychiatry journal was undertaken.

Data on elderly suicide rates for both sexes in the age-bands 65-74 years and $75+$ years were ascertained from the World Health Organization website (www.who.int/whosis/database/mort/table1.cfm). Data on suicide rates were collected for the latest available year and the median (range) of this latest year across the different countries was 2000 (1985-2003). Data on the total number of research publications were ascertained by manually reviewing (by RB) two leading geriatric psychiatry journals, International Psychogeriatrics and International fournal of Geriatric Psychiatry, for the five-year period 20022006. Only original research papers were considered. Editorials, review articles, commentaries, abstracts, letters and book reviews were excluded. If the research was carried out in more than one country then it was counted for each country involved in the research. The relationship between elderly suicide rates and the total number of research publications was examined using Spearman's correlation coefficient $(\rho)$ across different countries. 
A full data set was available for 87 countries. The total number of published research papers in the two journals was 1011 . There was a significant positive relationship between the total number of research publications and suicide rates in males aged $65-74$ years $(\rho=+0.19, \mathrm{p}=0.083)$, males aged $75+$ years $(\rho=+0.29, \mathrm{p}=0.007)$, females aged $65-74$ years $(\rho=+0.29, \mathrm{p}=0.007)$ and females aged $75+$ years $(\rho=+0.29, \mathrm{p}=0.007)$.

A causal relationship cannot be inferred from this cross-sectional ecological study. Moreover, there may be many different explanations for the findings including well-documented methodological problems in cross-national research on suicide (Shah, 2007a). Some countries, like the U.K., use suicide rates as a crude measure of outcome of mental health service provision (Shah, 2007b). Therefore, it is possible that higher elderly suicide rates may persuade research funding bodies to fund research in geriatric psychiatry and stimulate researchers to pursue research in geriatric psychiatry.

\section{References}

Chiu, H. F. K., Takahashi, Y. and Suh, G. K. (2003). Elderly suicide prevention in East Asia. International fournal of Geriatric Psychiatry, 18, 973-976.

Shah, A. K. (2007a). The relationship between suicide rates and age: an analysis of multinational data from the World Health Organisation. International Psychogeriatrics, 19, 1141-1152.

Shah, A. K. (2007b). Trends in elderly suicide rates in the United Kingdom over 24 years from 1979 to 2002. Medicine, Science and Law, 47, 56-60.

Shah, A. K. and De, T. (1998). Suicide and elderly. International fournal of Psychiatry in Clinical Practice, 2, 3-17.

\section{AJIT SHAH ${ }^{1,2}$ AND RITESH BHANDARKAR ${ }^{1}$}

${ }^{1}$ Old Age Psychiatry, John Connolly Unit, West London Mental Health NHS Trust, London, U.K.

${ }^{2}$ Ageing, Ethnicity and Mental Health, University of Central Lancashire, Preston, U.K.

Email: ajit.shah@wlmht.nhs.uk 